\title{
O ESPAÇO DO ESTADO NO NEOLIBERALISMO: ELEMENTOS PARA UMA REDEFINIÇÃO CRÍTICA
}

\author{
Felipe Nunes Coelho Magalhães ${ }^{1}$ \\ Universidade Federal de Minas Gerais
}

\begin{abstract}
Resumo: $O$ artigo se insere na discussão contemporânea acerca da cidade neoliberal, trazendo elementos teórico-conceituais para uma reavaliação do neoliberalismo como um modo de regulação capitalista centrado no Estado, não pautado por seu enfraquecimento, mas por sua reestruturação na direção de outro formato de Estado forte. Propõe-se que este reposicionamento carrega implicações importantes para a relação Estado/produção do espaço, trazendo também uma recuperação de interpretações que colocam o econômico como efeito do político-estatal, e não o contrário. Partindo de uma análise da literatura da gênese do pensamento neoliberal, o texto perpassa a literatura contemporânea acerca da biopolítica, do exercício de poder através de mecanismos de disciplinamento e agenciamento de subjetividades, culminando na leitura lefebvriana da relação Estado/espaço, ao apontar para transformações advindas do fortalecimento do Estado neoliberal na produção do espaço.
\end{abstract}

Palavras-chave: Neoliberalismo; Cidade Neoliberal; Teorias do Estado; Reestruturação do Estado; Estado Capitalista.

\section{STATE SPACES UNDER NEOLIBERALISM: ELEMENTS FOR A CRITICAL REDEFINITION}

Abstract: This paper engages in the current debate around the neoliberal city, bringing theoreticalconceptual elements for a reassessment of neoliberalism as a mode of capitalist regulation centered on the state, not defined by its weakening, but by its restructuring towards a new format of state strength. We propose that this repositioning brings important consequences for the relations between the state and the production of space, also evaluated through reinterpretations of the economic as an effect of the political/bureaucratic, and not its opposite. Departing from readings on the genesis of neoliberal political thought, the paper also approaches the contemporary literature on biopolitics, on the exercise of power through mechanisms of disciplining and the assemblage of subjectivities, culminating in the lefebvrean interpretation of state-space relations, finally pointing towards transformations that arise from the strengthening of the neoliberal state apparatus in the production of space.

Keywords: Neoliberalism; Neoliberal City; State Theories; State Restructuring; Capitalist State.

\footnotetext{
${ }^{1}$ Professor adjunto da Universidade Federal de Minas Gerais. Contato: felmagalhaes@ gmail.com.
} 
O debate acerca da cidade neoliberal, ou da produção do espaço na metrópole sob a égide do neoliberalismo, vem trazendo ricas contribuições para a teorização e a pesquisa acerca da cidade capitalista, com possíveis desdobramentos teóricos e práticos no contexto da semiperiferia e da América Latina. Este artigo se insere neste diálogo trazendo uma discussão teórica acerca da importância de se repensar a relação entre Estado, neoliberalismo e produção do espaço, a partir de um reposicionamento crítico do primeiro diante da (ultra propagada) ideologia do Estado mínimo, interpretando o neoliberalismo não como um processo que esvazia o Estado a favor da promoção do mercado, mas como um fortalecimento do Estado a partir de uma forma reestruturada de sua atuação. Não se trata, assim, de Estado frágil, mas de um Estado forte neoliberal, cujas consequências geográficas abrangem processos socioespaciais de grande envergadura e profundidade.

O neoliberalismo é abordado aqui como um processo multifacetado, abrangendo aspectos econômicos, políticos e culturais, que surge de uma filosofia política ligada a uma escola de pensamento econômico, dando origem a um receituário bem definido para a ação do Estado na regulação da acumulação, diferindo do liberalismo clássico tanto nos preceitos teóricos quanto na prática governamental, de diversas formas. Seu surgimento advém de um posicionamento político contrário ao Estado keynesiano, derivado da ciência econômica de inspiração clássica na Europa do pós-guerra, e também como resposta ao vínculo (apontado por esta nova plataforma) entre Estado forte e autoritarismo na trajetória alemã do Terceiro Reich, ao mesmo tempo se posicionando de maneira crítica frente ao liberalismo clássico e suas aplicações na formatação da ação do Estado. O segundo passo na gênese desta filosofia política que se tornaria receituário para a reestruturação do Estado traz implicações importantes para a produção do espaço e envolve a definição da "agenda do setor público" ideal para o afloramento de mercados, indicando um nexo causal que parte do Estado em direção à economia. Propõe-se, dessa maneira, uma análise do processo neoliberal no que diz respeito a uma primeira ligação com a produção do espaço a partir de sua faceta de forma de ação do Estado. Para tal, parte-se de uma leitura das raízes do pensamento neoliberal, terminando com uma breve apreciação da relação entre Estado, acumulação e espaço, que se faz necessária no debate presente acerca da relação entre neoliberalismo e produção do espaço.

\section{Neoliberalismo e Estado: redefinições}

Um momento pioneiro chave para o entendimento das origens do neoliberalismo, segundo Dardot e Laval (2014) e Foucault (2008), não é a criação da Sociedade Mont Pèlerin em conferência organizada por Friedrich Hayek na Suíça em 1947, como é tradicionalmente propagado, mas a realização do Colóquio Walter 
Lippmann no ano de 1938, em Paris, no Instituto Internacional de Cooperação Intelectual, instituição que viria a se tornar a UNESCO. Os dois eventos são interligados e dividem as mesmas intenções de renovação do pensamento liberal diante da hegemonia intervencionista naquele contexto, sendo que o segundo foi organizado por uma corrente minoritária no primeiro, e que viria a se tornar predominante nas décadas subsequentes (encabeçada neste período inicial por Ludwig von Mises e Friedrich Hayek, que se aproximavam mais do laissez-faire clássico do que a maioria presente no colóquio Walter Lippmann). O termo neoliberalismo foi proposto durante o colóquio pelo sociólogo e economista alemão Alexander Rüstow, justamente com a intenção de criar um distanciamento em relação ao liberalismo clássico - amplamente condenado na opinião pública, ainda naquele período, como a causa da grande depressão de $1929^{2}$, sustentando o apoio ao intervencionismo em moldes keynesianos.

A crítica ao intervencionismo partia de um comum acordo entre os dois grupos, de que o mecanismo de flutuação e definição de preços de acordo com dinâmicas de mercado, o principal responsável pela eficiência da mão invisível, estaria comprometido pelo imperativo do coletivismo, dirigismo, regulacionismo, da taxação e planejamento. Desta forma, os resultados negativos de dinâmicas de mercado sempre advinham da intervenção. Se há desemprego, por exemplo, é em função de políticas que mantêm os salários artificialmente elevados (salário mínimo, por exemplo, ou proibições de cortes de remunerações) em relação ao preço que a dinâmica de oferta e demanda de mão de obra definiria naturalmente. $\mathrm{O}$ distanciamento em relação ao liberalismo clássico se dava através da defesa de uma forma de ação do Estado proativa e incisiva, mas não necessariamente intervencionista nos padrões do Estado de bem-estar social. O governo neoliberal, já neste momento anterior à segunda guerra, era proposto como um Estado de direito com regras claras, bem definidas, e que sejam previsíveis pelos agentes econômicos, agindo em função de garantir as condições básicas para o livre mercado, mas sem intervir diretamente na esfera das transações econômicas, para que os agentes tenham espaço para fazerem o que bem entenderem e ao mesmo tempo possam incorporar nos seus cálculos racionais de risco e retorno/custo e benefício as regras do jogo e a forma com que o Estado as garante.

\footnotetext{
${ }^{2}$ Philip Mirowski; Dieter Plehwe. The road from Mont Pèlerin: the making of the neoliberal thought collective. Harvard University Press, 2009 (p. 13).
} 
Havia, no colóquio Walter Lippmann, a ideia de que "a independência da economia de instituições políticas e sociais era o erro fundamental da mística liberal, que levava a um desentendimento quanto ao caráter construído do funcionamento do mercado" (DARDOT \& LAVAL, 2014, p. 57). Ou seja, pressupunha-se a economia como derivada de leis fortes, garantidas pela força do Estado, e de uma ordem jurídica pré-definida tendo em vista a eficiência da operação do livre mercado, mas como uma entidade derivada dessas leis. Havia também uma crítica de que a teorização liberal do final do século XIX vinha se aproximando da incorporação de preceitos darwinistas (especialmente na obra de Herbert Spencer), tratando a sociedade como uma ordem natural, e nisso criava um distanciamento da prática governamental e da atividade de criação de leis e formulação de instituições, que por sua vez falhavam na regulação do capitalismo, permitindo o crescimento de monopólios e a profusão de crises diversas. Desse modo, o que se buscava naquele momento de crítica tanto ao liberalismo clássico quanto do intervencionismo keynesiano que era julgado como uma forma de autoritarismo, era uma série de princípios a guiar o intervencionismo liberal, e o primordial se torna justamente o princípio da competição. Dardot e Laval identificam uma série de argumentos nos trabalhos do filósofo Louis Rougier, o organizador do colóquio, que traçam essa linha de forma precisa:

O capitalismo competitivo não era um produto da natureza, mas uma máquina que demandava constante supervisão e regulação. (...) Romper com a 'fobia do Estado' como manifestada de forma exemplar em [Herbert] Spencer era uma coisa; estabelecer a fronteira que separa a intervenção legítima da ilegítima era outra. Como se poderia evitar as maneiras errantes de 'políticos demagogos' e 'doutrinários visionários'? O critério absoluto era o respeito pelos princípios da competição. De forma contrária a todos aqueles que defendiam que a 'concorrência mata a concorrência', Rougier, em acordo com todos os outros liberais, defendia que distorções na competição derivavam principalmente da intervenção do Estado, não de um processo endógeno. (...) No entanto, o que introduz uma discordância entre as posições é que para Rougier, a concorrência somente poderia ser estabelecida através da interferência do Estado (DARDOT \& LAVAL, 2014, p. 63).

A respeito do posicionamento do jornalista norte-americano Walter Lippmann - a partir de quem o colóquio foi nomeado em função de sua obra de 1937, A Reconstrução da sociedade, que havia sido traduzida para o francês como La Cité Libre, e que servira de referência inicial para os diálogos do colóquio - Dardot e Laval acrescentam que 
A palavra importante no vocabulário de Lippmann é adaptação. A agenda do neoliberalismo era guiada pela necessidade de adaptação constante de seres humanos e instituições a uma ordem econômica inerentemente variável. A política neoliberal deve incentivar essa operação atacando privilégios, monopólios e rendas não merecidas. Ela procura manter as condições operacionais do sistema competitivo (DARDOT \& LAVAL, 2014, p. 64-65).

Em Lippmann, esta visão vem acompanhada de uma perspectiva evolucionista em que seres humanos novos devem superar as qualidades de seres humanos antigos, num padrão econômico de eficiência que seria atingido através de uma política de adaptação à competição baseada em dois pilares: a eugenia e a educação, sendo esta última pautada, sobretudo, pela necessidade de se criar melhores competidores, o único parâmetro que justificava seu provimento através do Estado (DARDOT \& LAVAL, 2014, p. 66).

O elemento transversal capaz de sustentar um projeto de redefinição do projeto liberal seria um foco no Estado de direito como a base que garante que o livre mercado opere de forma eficiente e que os agentes se insiram nele de acordo com o princípio da competição. Citando Lippman ao final, Dardot e Laval argumentam que

a questão da arte de governar é central. Coletivistas e defensores do laissez-faire estavam errados por razões opostas a respeito da ordem política correspondente a um sistema de divisão do trabalho e trocas. O primeiro grupo desejava administrar a totalidade das relações dos seres humanos uns com os outros; o segundo acreditava que todas estas relações são naturalmente livres. A democracia seria o Estado de direito para todos; seria o governo a partir de uma lei comum feita por seres humanos: 'numa sociedade livre o Estado não administra os negócios dos homens. Ele administra a justiça dentre homens que conduzem seus próprios negócios' (DARDOT \& LAVAL, 2014, p. 68).

Esta visão da ação do Estado também parte de uma ideia evolucionista de que o governo se aprimora ao longo da história, de modo que as necessidades de regulação se apresentariam no próprio percurso e seriam incorporadas progressivamente nas regras. Há aí um ataque ao princípio do planejamento - que seria apresentado de forma mais radical em Hayek, como será exposto adiante - de que a ação do Estado deve seguir preceitos e objetivos definidos coletivamente de acordo com prioridades democráticas. O governo (neo)liberal estabelece regras claras para os indivíduos fazerem o que bem entenderem, definindo os limites para tal ação, que envolve também uma definição da ação do Estado (necessariamente coercitiva). Trata-se de criar as condições para que a competição entre indivíduos sirva ao suposto interesse coletivo, e estas condições são essencialmente jurídicas (e policiais). Este é um 
movimento que envolve uma segunda grande transformação em relação à analisada por Karl Polanyi no fim da sociedade baseada no mercado livre e no Estado liberal do século XIX, mantendo os preceitos daquele autor de que o econômico sempre deriva do político, mas separando intervencionismo de coletivismo, e fazendo surgir esta forma de intervencionismo em prol do mercado. Para Louis Rougier (apud DARDOT \& LAVAL, 2014, p. 56-57), ser liberal não é deixar que os carros dirijam como quiserem, em todas as direções (como no liberalismo do século XIX), e nem definir para cada carro seu horário de partida e seu itinerário (tal qual fazem os planejadores), mas sim saber impor um código de trânsito, que se adapte às condições de seu tempo. Portanto,

não nos enganemos. Não se tratava de uma questão de redução da quantidade de poder exercida por esta autoridade, mas de mudar o tipo de autoridade, o campo de seu exercício. Dever-se-ia garantir um direito comum ${ }^{3}$ que governaria interesses indiretamente. Somente um Estado forte poderia fazer as pessoas respeitarem tal direito comum. Como Lippmann insistia em todas as suas publicações, era necessário renunciar à ilusão de um poder governamental frágil tal qual o que se generalizou no século XIX. A grande crença liberal num Estado discreto e supérfluo já não era mais pertinente desde 1914 e 1917 (DARDOT \& LAVAL, 2014, p. 71).

Outro aspecto fundamental já presente no Colóquio Walter Lippmann era a ideia de que o governo deveria ser um governo das elites competentes, "cujas qualidades seriam o exato oposto à mentalidade mágica e impaciente das massas" (DARDOT \& LAVAL, 2014, p. 72). O problema da democracia para esse grupo seria justamente este, como manter o governo protegido das intempéries das vontades e interesses pouco razoáveis das maiorias. Esse é um ponto fundamental na ponte entre o ideário neoliberal e o início de sua aplicação prática por parte de governos como resposta à crise do keynesianismo da década de 1970 - interpretada naquele momento como uma crise de excesso de democracia.

Este quadro amplo que se consolida no Colóquio informa um modo de liberalismo interventor renovado que é aplicado na Alemanha do pós-guerra sob a denominação de ordo-liberalismo (representado no Colóquio principalmente nos trabalhos de Walter Eucken e Willhelm Röpke), justamente em função da crença na necessidade de ordenar a competição e o livre mercado ao mesmo tempo em que se mantém distância da experiência coletivista que era marcada naquele país pela

\footnotetext{
${ }^{3}$ Do inglês common law, indicando uma ligação dos preceitos desta formulação jurídica incremental e acumulativa, em que as leis supostamente se aperfeiçoam ao longo do tempo, com o modelo jurídico utilizado na Inglaterra e suas ex-colônias.
} 
experiência do totalitarismo. Progressivamente, este modelo se transforma através da consolidação desta combinação entre preceitos liberais e ajustes estatais na direção da chamada economia social de mercado, que corresponde ao Estado de bem-estar europeu do pós-guerra em sua versão alemã. É interessante notar que a versão do neoliberalismo que viria a se tornar hegemônica no mundo também tem um ponto de apoio importante na vinculação do coletivismo com o autoritarismo, na obra de Friedrich Hayek, mas aponta o barco na direção oposta da trajetória do ordoliberalismo alemão, para rumos menos intervencionistas e menos críticos à ideologia da ordem natural do mercado do liberalismo clássico (o que não significa prescindir de um Estado forte neoliberal, e em termos teórico-conceituais, na ideia de que a esfera econômica é derivada da política ${ }^{4}$ ). Na história do pensamento, os antecedentes dessa versão do pensamento neoliberal, que era minoritária no Colóquio Walter Lippmann, se situam na ciência econômica austríaca, mais especificamente nos trabalhos do economista que é considerado o pai fundador daquela escola, Carl Menger, quem também foi um dos protagonistas na revolução marginalista na teoria econômica e o (co)formulador da ideia de utilidade marginal - conceito central na teoria econômica ortodoxa contemporânea ${ }^{5}$.

Menger formularia uma crítica tanto à concepção clássica (de Adam Smith e David Ricardo) do valor baseado nos custos de produção, quanto à teoria marxista do valor ${ }^{6}$, propondo que os preços são definidos nas margens, em função da utilidade marginal do uso de determinado bem ou serviço que entra como insumo na interação de compradores e vendedores no mercado. Trata-se de um aprofundamento (altamente matematizado e formalizado em modelos abstratos) num recorte do argumento de Adam Smith acerca da mão invisível e da eficiência produtiva e distributiva do livre mercado, com esta alteração em relação à teoria do valor, e uma postura muito mais radical em relação à crença na eficiência do livre mercado. Menger busca complementar as formulações dos clássicos acerca da eficiência dos mecanismos de oferta e procura e da definição de preços a partir dessas interações com uma abordagem a respeito do comportamento do consumidor, inserindo um componente subjetivo referente à atribuição de valor às mercadorias por parte dos consumidores em potencial, de acordo com a utilidade adicional, ou marginal, que aquele bem ou serviço em oferta agregaria a seu comprador - o que

\footnotetext{
${ }^{4}$ Aspecto que será aprofundado adiante, e que curiosamente reúne em comum acordo autores em posições opostas no espectro político, desde Hayek e Friedman até Karl Polanyi e alguns contemporâneos de orientação anarquista como David Graeber, obviamente com implicações radicalmente distintas.

${ }^{5}$ No mesmo período que Menger, e de forma independente, o matemático e economista francês Leon Walras e o economista inglês William Jevons - os outros grandes expoentes da revolução marginalista na teoria econômica - proporiam elaborações semelhantes, centradas no estudo das alterações marginais para o bom entendimento do valor e da dinâmica econômica.

${ }^{6}$ Que opera dentro deste mesmo domínio, mas inserindo o mais-valor a partir da teoria ricardiana do valor-trabalho (que centraliza o quantum de trabalho contido em determinado produto como a fonte de seu valor) como um pivô de inversão crítica e de politização da teoria do valor.
} 
viria se tornar um ponto de partida para a microeconomia muito desenvolvida após a revolução marginalista. Tal subjetividade na determinação do valor em função da utilidade marginal é um atributo próprio do consumidor, e pode variar de acordo com circunstâncias externas, mas se trata de um aspecto essencialmente individual e determinante nas transações econômicas.

Nesse sentido, o mercado se torna o grande ente solucionador de problemas humanos, pois se tudo puder ser comprado e vendido sempre haverá um encontro entre oferta e demanda em que indivíduos, agindo estritamente em função de seu interesse individual e de suas necessidades subjetivamente determinadas, promoverão trocas mutuamente benéficas que, em seu conjunto, necessariamente redundam no bem-estar coletivo (através de um agregado de utilidade/satisfação mais elevado para todos). Valores altos atribuídos a determinado bem ou serviço em função de uma utilidade marginal individual elevada que o acesso a ele proporciona necessariamente engendram sua oferta no mercado, pois criam oportunidades lucrativas para os ofertantes em potencial. Ou seja, trata-se de uma elaboração teórica que se somaria ao argumento da teoria econômica clássica na defesa da eficiência do livre mercado a partir de um princípio (considerado libertário por alguns dos próprios autores desta vertente) de autodeterminação individual: não se pode fazer escolhas por outras pessoas, pois o escalonamento de prioridades que define a escolha a partir da atribuição de valor a cada possibilidade disponível depende de julgamentos subjetivos intrínsecos ao indivíduo, sendo que a crítica aos clássicos se concentraria na determinação do valor sem levar em conta a utilidade marginal em função de valorações individuais do consumidor. Como detalhado adiante, este princípio seria usado extensivamente por teóricos do neoliberalismo contra políticas públicas do Estado de bem-estar social de caráter coletivo.

$\mathrm{Na}$ década de 1880, a atuação de Menger na Universidade de Viena e seus debates com a escola historicista alemã de economia (escola de pensamento que teria influência significativa em Werner Sombart e Max Weber) atrairiam uma série de discípulos, dentre eles o economista Eugen Böhm von Bawerk, que publicaria extensas críticas à obra marxista no final do século XIX, talvez as primeiras do gênero, partindo de premissas liberais e da ciência econômica ortodoxa. Dentre os alunos de von Bawerk, estava Ludwig von Mises, que se tornaria o principal difusor da escola austríaca em sua geração, considerado por muitos como a figura mais proeminente do grupo. Mises conduzia seminários informais particulares frequentados pela geração seguinte de economistas da Escola Austríaca, sendo que após o contato com a obra Socialismo: uma análise econômica e sociológica, de autoria de von Mises, Friedrich von Hayek entraria para o grupo. Trata-se de uma crítica pioneira ao socialismo real, publicada originalmente em 1922, já apresentando as raízes das críticas libertárias (à direita) de Hayek ao Estado keynesiano.

Em 1931, Hayek migra para a Inglaterra e se torna professor de Economia da London School of Economics, onde representaria uma corrente contrária tanto ao 
keynesianismo nascente quanto à ortodoxia em sua vertente marshalliana (na qual o próprio Keynes formou-se), predominante naquele período. Assim como a escola austríaca em seu conjunto, a produção acadêmica de Hayek teria um caráter essencialmente marginal no contexto do predomínio keynesiano entre as décadas de 1930 e 1970 - tanto no campo epistemológico, quanto na sua aplicação prática à orientação da ação do Estado. Mas é sua obra publicada durante a Segunda Guerra Mundial que constitui um corpo teórico e um ponto de partida importantes para que o neoliberalismo viesse a ganhar visibilidade e influência até se tornar, a partir da crise do modo de regulação fordista-keynesiano da década de 1970, um modelo de orientação da ação do Estado visando a reestruturação amplamente adotado pelo mundo. Por estabelecer as bases do modelo de neoliberalismo que se tornaria hegemônico posteriormente, O caminho da servidão (HAYEK, 1944) é uma obra que merece tratamento mais aprofundado para prosseguir no argumento que buscamos construir, estabelecendo ligações com o espaço através de uma triangulação Estado-capital-geografia. Essa leitura é bastante reveladora da natureza do neoliberalismo na prática e do distanciamento que se produz em relação aos preceitos teóricos que orientam o projeto.

\section{Hayek e o caminho da servidão ao mercado}

O primeiro aspecto marcante d'O caminho da servidão é seu tom alarmista, num alerta para o risco dos países aliados na Segunda Guerra estarem caminhando na direção da Alemanha nazista em função do Estado cada vez mais forte, interventor, autoritário do ponto de vista do autor. Hayek defendia o liberalismo como um ideário intrinsecamente progressista, argumentando que este caráter teria sua imagem distorcida em função de uma falsa associação entre individualismo e egoísmo. Hayek considerava o indivíduo a base da construção do ideário civilizatório ocidental, e por isto atacava a associação entre pensamento progressista e socialismo que predominava naquele período. $\mathrm{O}$ autor argumenta também que o planejamento governamental moderno tem raízes na Alemanha do século XIX, traçando ligações do prussianismo - que dá origem a uma experiência de crescimento econômico orientado pelo planejamento estatal num paradigma fora do laissez-faire dominante naquele período - tanto com o socialismo quanto com as origens do totalitarismo hitlerista, sempre operando nestes termos, da vinculação entre o inimigo na guerra e a ameaça interna contida no Estado interventor. No desenvolvimento deste argumento da incoerência absoluta entre planejamento e liberdade, Hayek introduz uma série de princípios baseados nos preceitos do marginalismo mengeriano que se tornariam centrais na cartilha do neoliberalismo, girando em torno da ideia de que a ação do Estado cria distorções no sistema de preços que sinaliza aos indivíduos o que fazer, gerando obstáculos para que o 
mercado livre resulte em maior bem-estar coletivo (entendido como um somatório de utilidades individuais, no sentido da teoria econômica ortodoxa do termo).

A individualização das soluções para problemas coletivos é sempre defendida no discurso neoliberal, em função do princípio da liberdade individual de escolha decorrente das atribuições subjetivas de utilidade individual a opções distintas disponíveis no mercado. O provimento de habitação social, por exemplo, seria atacado por Milton Friedman (1962, p.178) com o argumento de que se trataria de uma escolha paternalista imposta aos indivíduos. Por isso, Friedman considerava que a transferência direta de dinheiro aos beneficiários seria mais eficiente e teria melhores resultados em termos de utilidade gerada. Portanto, é neste sentido que a noção de liberdade ganha proeminência no discurso neoliberal: ele parte de um ataque ao Estado paternalista - que infantiliza o cidadão, tratando-o como sujeito interditado e que interfere na capacidade individual de determinação e escolha -, sendo o acesso ao dinheiro para que as pessoas resolvam seus próprios problemas através do mercado sempre um caminho preferível ao do provimento da solução coletiva para esses problemas pelo Estado. É notável que Friedman (1962, p. 192) também defende a transferência direta de renda (em padrões muito semelhantes ao que seria aplicado no Brasil com o Programa Bolsa Família) como uma forma de política de auxílio aos pobres mais eficiente que a formulação de políticas públicas de provimento direto de serviços coletivos que atendessem a estes grupos mais vulneráveis.

Assim como para os participantes do Colóquio Lippman, para Hayek é necessário que existam leis fortes para que o mercado funcione bem, mas sempre com limites. O momento em que aparece a defesa do planejamento econômico é em relação aos monopólios naturalmente resultantes do mercado, mas mesmo aí é apresentada a crítica de que monopólios geralmente são criados por regulações, legislações em excesso e intervenção (como no caso dos grandes conglomerados empresariais alemães), e que o planejamento é necessariamente impregnado pelo problema da onisciência impossível, sendo que as informações e fatos a serem levados em consideração são tão numerosos e complexos que não existe a possibilidade de se obter qualquer forma de eficiência no resultado. Desse modo, segue o argumento, o melhor planejador é sempre o mercado, através dos sinais que ele mesmo dá a seus agentes através da dinâmica dos preços, permitindo uma descentralização total das decisões, no extremo oposto do planejador onisciente e bem intencionado - mais uma vez traçando ligações com o plano do autoritarismo.

Para Hayek, os sistemas coletivistas pressupõem a definição de um objetivo único, de um "bem comum", para o qual a ação coletiva organizada no âmbito do Estado deve mirar. Isso implica um código de ética não somente comum, mas que também inclua tudo. Este seria um pré-requisito para o planejamento, e impossível de ser alcançado: 
A direção de todas as nossas atividades de acordo com um plano único pressupõe que para cada uma de nossas necessidades se atribua uma posição numa ordem de valores que deve ser bastante completa para tornar possível a escolha entre as diferentes alternativas que o planejador tem diante de si. Pressupõe, em suma, a existência de um código ético completo, em que todos os diferentes valores humanos estejam colocados em seu devido lugar (HAYEK, 2010, p. 75-76).

O corolário, mais uma vez, é que democracia só é possível no capitalismo: socialismo implica planejamento, que leva ao Estado grande, que, por sua vez, conduz ao autoritarismo. Segundo Hayek, o percurso da Alemanha do período entreguerras teria sido justamente este, com um estado de caos resultante da herança da primeira guerra em conjunto com a ação do Estado interventor (da década de 1920). A gravidade da crise teria justificado a aceitação de um regime "forte", que tiraria proveito das estruturas centralizadoras previamente construídas (p. 83-84). O argumento normativo acerca do papel do Estado para Hayek gira em torno de um Estado de direito forte, pautado em primeiro lugar pela garantia do direito de propriedade:

Nossa geração esqueceu que o sistema de propriedade privada é a mais importante garantia da liberdade, não só para os proprietários mas também para os que não o são. Ninguém dispõe de poder absoluto sobre nós, e, como indivíduos, podemos escolher o sentido de nossa vida - isso porque o controle dos meios de produção se acha dividido entre muitas pessoas que agem de modo independente. Se todos os meios de produção pertencessem a uma única entidade, fosse ela a "sociedade" como um todo ou um ditador, quem exercesse esse controle teria poder absoluto sobre nós (HAYEK, 2010, p. 115).

Esta abstração distanciada é um dos preceitos básicos do Estado forte neoliberal, que retoma a máxima do laissez-faire clássico em sua versão francesa tal qual identificada por Foucault (2008), de que o bom governo é aquele que governa o mínimo possível para que o mercado funcione. Nesse sentido, Hayek situa a função do Estado na defesa da definição de regras claras e bem definidas para que os indivíduos possam se adaptar da melhor forma possível a suas atividades privadas e se posicionar de forma a maximizar suas utilidades de acordo com seus atributos específicos. Como indicado por Foucault (2008, p. 237), neste ponto de vista o Estado de direito não pode ter objetivos coletivos bem definidos - tal qual atacar o problema da desigualdade -, pois estes são arbitrários e abrem a possibilidade de que sejam usados por governos autoritários, sendo que a ação do Estado precisa ser sempre previsível para os agentes econômicos. 
A dicotomia entre a intervenção ou a não intervenção do Estado é inteiramente falsa, e o termo laissez-faire é uma definição bastante ambígua e ilusória dos princípios em que se baseia uma política liberal. Está claro que todo o Estado tem de agir, e toda ação do Estado implica intervir nisto ou naquilo. Mas não é isso que vem ao caso. O importante é saber se o indivíduo pode prever a ação do Estado e utilizar esse conhecimento como um dado na elaboração de seus planos particulares - o que significa que o Estado não pode controlar a forma como seu mecanismo é empregado e que o indivíduo sabe exatamente até que ponto será protegido contra a interferência alheia - ou se o Estado está em condições de frustrar os esforços individuais (HAYEK, 2010, p. 95-96).

Este é um modelo abstrato de orientação da ação do Estado cujas tentativas de aplicação prática interagiriam com formações econômico-sociais e espaciais concretas e heranças históricas específicas, dando forma a variadas experiências de "neoliberalismo na prática", a partir dos resultados destas interações. Como ressaltado por Peck (2010), o projeto neoliberal se caracteriza pela impossibilidade de sua realização plena: ele sempre terá uma agenda a cumprir na direção de um conjunto de preceitos, e seus ideólogos sempre acreditarão que terão conseguido pouco diante do que ainda precisará ser conquistado. Portanto, a partir desta série de princípios abstratos, o que existe na prática sempre é uma versão (em variações histórico-geográficas) do neoliberalismo, imperfeita segundo os objetivos do próprio projeto, misturada com resquícios históricos do Estado e da economia de acordo com suas características em cada lugar, e, sobretudo, interagindo com a sociedade, também de acordo com suas características formadas por trajetórias anteriores específicas.

No contexto do pós-guerra, um personagem fundamental na sequência desta linhagem iniciada na ciência econômica austríaca de Carl Menger é Milton Friedman. Assim como Hayek, bem informado quanto à noção de que ideias e valores dão forma ao real, Friedman tem seu trabalho muito estrategicamente pautado pela consciência da importância de agir no campo do debate público, direcionando-se a audiências amplas e buscando vencer batalhas no campo das ideias a fim de que elas tivessem aceitação na sua aplicação prática quando o momento oportuno para tal viesse. A obra síntese de Friedman neste período, publicada em 1962, no contexto da Guerra Fria, é Capitalismo e Liberdade, texto que continua a tarefa de defender as premissas do liberalismo clássico através da estratégia de vincular seu inimigo interno naquela conjuntura histórica, o Estado keynesiano, ao autoritarismo do inimigo externo, os países do bloco do leste. Friedman procura demonstrar como a intervenção proativa sempre engendra resultados inesperados negativos, por mais bem intencionados que sejam os 
planejadores por trás delas: salário mínimo resulta em maior desemprego, habitação social concentra pobreza e não a alivia, seguridade social cria dependentes que se tornam incapazes etc. $\mathrm{O}$ autor defende frequentemente o princípio de que o acesso dos beneficiários de políticas públicas ao dinheiro é sempre mais eficiente que o provimento público do serviço, pois abre um leque de escolhas (liberdade) ao beneficiário, que pode usufruir do dinheiro como bem entender, e ainda se beneficiar de serviços providos pelo mercado, mais eficientes em função da concorrência a que estão sujeitos.

No entanto, neste encadeamento entre história das ideias e sua aplicação prática que aqui se delineia brevemente, o argumento chave daquela obra que torna seu autor uma figura fundamental na ponte com a transformação desta série de princípios em políticas econômicas para os governos centrais de diversos países é o ataque à explicação keynesiana para a grande crise de 1929 e a introdução do monetarismo como o diagnóstico correto, pré-anunciando um reinado desta doutrina no campo da macroeconomia centrado na Escola de Chicago sob seu comando. O monetarismo parte da teoria quantitativa da moeda, já anunciada em Stuart Mill, e desenvolvida por von Mises e Irving Fisher nas décadas de 1920 e 1930, que associam nível de preços à quantidade de moeda em circulação. Deste ponto de vista, a crise de 1929 teria ocorrido em função das falhas na atuação do banco central americano em manter a quantidade de moeda em circulação muito restrita, provocando uma recessão que poderia ter sido evitada com uma política monetária apropriada. A crise do fordismo/keynesianismo da década de 1970 não tinha explicações satisfatórias do ponto de vista keynesiano dominante, pois era marcada por uma combinação entre inflação e desemprego, o que é uma incoerência na perspectiva daquela escola. Friedman e os monestaristas ganham enorme credibilidade e atenção ao oferecer a explicação através da inflação ligada ao excesso de moeda em circulação, que teria que ser resolvida através de uma política monetária restritiva, que causaria algum desemprego como efeito colateral, mas resolveria o problema dos preços. Esse prognóstico seria aplicado pelo banco central norte-americano no final da década de 1970, aumentando repentinamente os juros daquele país para um recorde histórico, o que teria consequências abissais para o Brasil e toda a América Latina na deflagração da crise da dívida do início da década de 1980, resultante da tradução prática da doutrina da Escola de Chicago na inauguração de um novo modelo de política econômica anti-inflacionária, sendo a crise latino-americana daquela década um resultado direto desta mudança de direção nos países de centro, sobretudo os EUA.

A história de submissão às exigências dos credores e das instituições multilaterais como condições para a renegociação da dívida pública e todas as suas consequências - que constitui uma servidão da sociedade ao mercado - é amplamente conhecida, e escapa ao escopo deste ensaio. O controle da dívida pública - que crescera exponencialmente no período da crise do keynesianismo, em função de tentativas de se reativar o crescimento através do gasto público - se torna um canal de entrada e 
imposição antidemocrática de uma agenda mais ampla. Da defesa do neoliberalismo como única forma de democracia verdadeira em Hayek e Friedman até a sua imposição autoritária no caso chileno sob Pinochet e, posteriormente, nas políticas exigidas por credores e agenciadas por instituições multilaterais sem representação democrática alguma há uma trajetória que perpassa o Estado e sua ampla transição de um capitalismo monopolista sob seu comando para esta nova forma de gestão autoritária da esfera econômica e, sobretudo, da população - tendo a democracia contra, como um ente exterior e na metrópole como uma forma de alteridade. $\mathrm{O}$ caminho da servidão hayekiano culmina na servidão ao mercado.

\section{Trajetórias encadeadas: Estado, capital e espaço}

Partindo do ponto de vista comumente assumido como pressuposto por alguns teóricos de orientação anarquista, e que constitui parte das inúmeras divergências daquela tradição com o cânone marxiano desde os primórdios deste, propõe-se um parêntese para inserir o Estado na discussão numa inversão de premissas estruturalistas clássicas: a relação entre acumulação capitalista e o Estado. Ressaltase o argumento de que a crítica ao estruturalismo baseado no determinismo econômico não pode ter na sua sequência uma simples inversão de estruturas, inserindo o plano simbólico ou a política na base: há uma dialética diversificada num pluralismo mais amplo de esferas e momentos, que são mutuamente definidores e divisíveis em partes menores, que também participam dessa criação de vetores lançados na direção de outros domínios, bem como da recepção de influências advindas destes.

O que Harvey (2011, p. 104) chama de "esferas de atividade" na sua análise dos formatos da trajetória histórica do capitalismo é uma analogia útil para esta perspectiva. Trata-se de sete esferas que se retroalimentam e se transformam em conjunto, sendo que os momentos de protagonismo são intercambiados entre elas ao longo do tempo. As esferas propostas por Harvey são: "tecnologias e formas de organização, relações sociais, arranjos institucionais e administrativos, processos de produção e de trabalho, relações com a natureza, reprodução da vida cotidiana e da espécie, e concepções mentais do mundo" (HARVEY, 2011, p.104). Trata-se de uma ampliação e diversificação de uma visão dialética da história e da mudança social coerente com o pluralismo epistemológico (BARNES \& SHEPPARD, 2010) aqui invocado. Inserir o Estado como esfera de onde saem vetores responsáveis pela gênese do capitalismo e por sua reprodução histórico-geográfica envolve manter este argumento nesta perspectiva mais ampla, em que existem outras esferas agindo simultaneamente nesta relação, e o capital, obviamente, reage, redefine o Estado, o transforma de acordo com suas exigências - sendo que estas entram em conflito com outras tentativas de influência advindas de outras zonas. Trata-se de uma teia com nós interligados em mútua determinação que em partes se assemelha ao rizoma 
(DELEUZE \& GUATTARI, 1995) e em outras a estruturas arbóreas, com raízes, ramificações e sub-ramificações ligadas por um tronco único. O Estado é justamente uma destas partes: se caracteriza por raízes bem definidas que criam um tronco forte e ramificações diversas.

O capital não se realiza sem a existência de diversos pré-requisitos providos pela autoridade violenta do aparato estatal: direito de propriedade privada, garantia de contratos, leis, polícia e prisões, moeda única, infraestrutura física e institucional, fronteiras etc. Num segundo nível de análise e inserindo o plano do processo histórico, não existe acumulação de capitais sem a passagem de determinada sociedade pelo processo eminentemente geográfico de acumulação primitiva que garanta as condições básicas para a realização do capital, sobretudo no que diz respeito à disponibilidade de mão de obra sem alternativas viáveis em vista a não ser sua sujeição ao trabalho remunerado (sendo a concentração fundiária no meio rural um elemento fundamental desta primeira premissa). Considerando que este processo de acumulação primitiva é em grande medida realizado e/ou garantido pelo aparato repressor estatal - e ocorre em cada lugar a partir de uma trajetória histórica específica, sendo os cercamentos ingleses do século XVI radicalmente diferentes das sesmarias e da distribuição de terras das companhias hereditárias promovida pelo Império brasileiro do século XIX, e da contínua reprodução da restrição do acesso à terra aos pobres no Brasil (HOLSTON, 2013) -, a relação Estado-sociedade é a relação fundamental sobre a qual o capital se estabelece.

A revolução industrial foi o processo classicamente considerado embrionário pela teoria marxista, com um enfoque excessivamente voltado para as transformações (socioespaciais, inclusive) daquele período histórico, sem dedicar muita atenção ao contexto político-institucional e à trajetória anterior a ele, que está por trás de algumas dinâmicas decisivas para a decolagem da produção industrial inglesa (como o pioneirismo da revolução burguesa na Inglaterra, ocorrida um século antes de sua equivalente continental), analisadas por alguns autores proeminentes do próprio cânone marxiano. Argumentamos que, de forma mais ampliada, o capital se estabelece a partir de formas específicas de governamentalidade (no sentido empregado por Foucault, 2008) e na relação Estado-sociedade que começa a ser construída na revolução burguesa.

Hobsbawm (1968) propõe que o crescimento exponencial do comércio da Inglaterra com o resto do mundo ao longo do século XVIII, em função da marinha mercante inglesa e da política externa ligada a interesses comerciais, fez crescer muito a demanda por produtos ingleses, garantindo mercados para a revolução industrial escoar sua produção. Desse modo, é imprescindível analisar a revolução industrial sem perder de vista estes processos de transformação do Estado a partir da tomada do poder pela burguesia inglesa no final do século XVII. Há uma transição entre o imperialismo mercantilista e o imperialismo do Estado capitalista que tem a revolução industrial no meio, mas por trás da própria revolução industrial há essa transformação do mercantilismo metalista naquilo que viria a ser o modelo de 
política externa para a promoção do crescimento capitalista interno (presente até os dias atuais, como nas políticas externas dos Estados nacionais visando a garantia de mercados). Outra referência importante está no trabalho de Bill Warren (1980), que propõe a interpretação - criticando a visão leninista, inclusive, do imperialismo como estágio avançado do capitalismo - de que seria o imperialismo o embrião do capital, sem o qual o crescimento interno da indústria inglesa não pode ocorrer, e que depois se tornaria uma válvula de escape fundamental para a gestão dos estrangulamentos que surgem à expansão capitalista, na forma do imperialismo do século XIX na colonização do subcontinente indiano e da partilha da África. Este colonialismo centrado nas grandes potências industriais como forma de se criar válvulas de escape e maiores possibilidades de expansão para a acumulação capitalista cria uma relação dialética de retroalimentação entre Estado e capital que persiste no mundo contemporâneo. Não se trata de abandonar esta perspectiva da relação de mão dupla ali existente, mas de ressaltar, através deste breve recurso à história e às origens da decolagem industrial no mundo, o fato de que a interação capital-Estado é uma relação de forças recíprocas, que se influenciam e se apoiam mutuamente (em muitos casos se tornando um ente simbiótico de partes indistinguíveis), e não uma via de mão única partindo da infraestrutura da produção e definindo instituições superestruturais de acordo com suas necessidades - nem mesmo através da tentativa de relativização da determinação "somente em última instância", pois se trata, antes de tudo, de uma forma de dominação política. Uma ilustração desse argumento é o fato de que os grandes ideólogos do neoliberalismo sempre prognosticam receitas de "desenvolvimento" em economias periféricas a partir de formas específicas de formatação de suas instituições, denominando os países africanos, que tentam , mas, não conseguem garantir condições básicas para a decolagem inicial do processo de acumulação vinculado aos mercados globais (geralmente através do incentivo às exportações de recursos naturais), como Estados fracassados.

Outra forma de demonstrar o mesmo corolário é através da desmistificação de algumas premissas liberais - iniciadas em Adam Smith e atualmente propagadas em livros-texto introdutórios à ciência econômica - acerca das origens da moeda. Smith parte do pressuposto de que há uma propensão humana às trocas, ao escambo, ao comércio, e à divisão do trabalho (o que se torna um fundamento básico da ciência econômica contemporânea, através do individualismo metodológico, da teorização da escolha racional etc.). Um breve percurso pelo olhar antropológico pode ser útil para se revelar alguns pressupostos falsos - e que são centrais para os preceitos básicos da economia clássica. O principal exemplo é o mito da origem do dinheiro como um facilitador das trocas: a economia clássica parte do pressuposto de que antes de existir a moeda, a prática do escambo limitava o mercado, pois um fabricante de ferramentas que precisasse de tecidos precisaria encontrar o seu diametralmente oposto: um fabricante de tecidos que precisasse de ferramentas. Teria surgido, assim, de forma espontânea e derivada de uma racionalidade coletiva 
em moldes modernos, uma instituição que cria a moeda com o intuito de potencializar essas trocas no mercado, que por sua vez faz surgir o crédito, a partir do surgimento da moeda.

Provando a falácia deste mito de origem, Graeber (2011) chama atenção para que tal economia de escambo nunca existiu. Os arranjos em sociedades sem dinheiro sempre envolveram esquemas complexos de doações e trocas de presentes de forma competitiva (em que aqueles que não conseguissem retribuir presentes generosos muitas vezes suicidavam-se), e/ou a organização da acumulação de bens posteriormente redistribuídos, no caso das sociedades com autoridades políticas centralizadas. Segundo Graeber, a moeda surge a partir do crédito como uma forma de nota promissória de garantia ao credor emitida pelo próprio devedor, e que passa a circular num mercado secundário, tendo seu valor ligado à credibilidade do devedor (que frequentemente era um pequeno mercador utilizando o instrumento para pagar fornecedores). O surgimento da moeda emitida por autoridades governamentais é ligado à formação de forças armadas constituídas de soldados contratados, gerando o ciclo escravização de capturados em guerra para o trabalho em minas de metais preciosos - utilização dos metais para cunhar moeda e remunerar soldados - cobrança de impostos em moeda emitida dos súditos para garantir que a remuneração aos soldados tenha valor de troca no mercado. Os mercados surgiram muito anteriormente a este processo, mas ganharam uma nova escala nesta relação com o poder central através da cobrança de impostos, o que ocorre nas civilizações da era axial (entre 200-800 a.C.) paralelo a um aumento enorme na população escrava nestes primeiros grandes impérios, que eram conquistados através de investidas dos exércitos de mercenários sobre outros grupos e sociedades distantes.

Uma referência adicional para a centralidade do Estado na acumulação capitalista é a parte da obra lefebvriana dedicada ao Estado. Um fato bastante curioso no longo percurso de apropriação dos escritos de Henri Lefebvre acerca da cidade, do urbano e da produção do espaço, que aparece na teorização crítica em torno desses temas desde a década de 1970, é a pequena atenção dada aos seus trabalhos sobre o Estado $^{7}$, imediatamente posteriores à obra seminal, A produção do espaço (LEFEBVRE, 1974), na qual o tema do Estado já era fundamental, sobretudo nas proposições ligadas ao chamado espaço abstrato ${ }^{8}$. O diálogo com a obra de Henri Lefebvre na Geografia e nos estudos urbanos deu pouca atenção às teorizações daquele autor em De L'état, conjunto de obras que traz contribuições importantes para se pensar o Estado na contemporaneidade, sua relação com o espaço e a própria globalização (cuja discussão Lefebvre antecipa em alguma medida, já em meados dos anos 70). Como perguntam Neil Brenner e Stuart Elden: "mas por que o Estado?

\footnotetext{
${ }^{7}$ Ver Lefebvre (1976; 1976b; 1977; 1978), e Lefebvre et al (2009).

${ }^{8}$ Que parece ter sido o ponto central a partir do qual aquele autor abre um flanco da sua obra maior acerca da cidade e do espaço social para analisar o Estado, enquanto ente produtor do espaço abstrato na contemporaneidade.
} 
Para Lefebvre, a resposta é simples e direta - 'porque o Estado, e tudo que ele envolve implica, se encontra no seio da modernidade e do chamado mundo moderno",9.

O Estado realizou o que nenhuma religião ou igreja conseguiu: conquistar o mundo, atingir a universalidade, ou pelo menos a generalidade, entrando com o mercado mundial na definição do que consiste o Planetário. O que é um processo extraordinário. Começando no século XIX, ele se acelera no XX, e se precipita com as guerras mundiais (LEFEBVRE, 1976, p. 11).

Lefebvre propõe a ideia do Modo de Produção Estatal como uma forma de se reunir a crítica ao produtivismo na sociedade contemporânea, tanto na sua vertente do socialismo real da experiência soviética quanto na acumulação capitalista sob as democracias liberais, ressaltando a centralidade do Estado por trás da produção em ambos. Assim, pensando nos termos do Modo de Produção Estatal, o neoliberalismo se torna uma nova rodada a partir do desmantelamento do aparato fordistakeynesiano que Lefebvre analisa - em pleno declínio - nesta obra. Uma das críticas comumente direcionadas a esta abordagem lefebvriana a respeito do Estado é justamente que ela se torna datada no momento em que o fordismo keynesiano entra em crise naquele mesmo período, no caso dos países do norte global, em que Lefebvre se debruçava sobre estes textos. Contudo, como demonstrado acima, abordar o neoliberalismo como forma de ação do Estado (e não como sua ausência) reafirma a validade da abordagem lefebvriana e seu enfoque sobre a relação espaçoEstado $^{10}$. Esta nova forma de governo do capital opera necessariamente a partir do legado deixado pelos formatos em que o espaço fordista-keynesiano toma em cada contexto histórico-geográfico. E, no entanto, trata-se do econômico como efeito do político, e do capital como derivação do Estado, mesmo se assumindo uma posterior via de mão dupla nessa relação: a impressão de que o neoliberalismo corresponde a um Estado ausente se deve a uma visão do Estado ainda presa a seu formato fordista-keynesiano - ou de situações específicas, como a que ocorre na metrópole brasileira, em que alguns bolsões de aparente ausência da autoridade estatal resultam da relação dessas áreas com o próprio Estado keynesiano em seu formato semiperiférico, que (como em Milton Santos) produz o espaço da modernidade incompleta, seletiva, dependente, e autoritariamente negligencia grandes porções da

\footnotetext{
${ }^{9}$ Em Lefebvre et al (2009. p. 2), citando Lefebvre em Le Retour de ladialectique.

${ }^{10}$ Ademais, aquele autor não deixa de reconhecer os sinais de transformação na direção do neoliberalismo já naquele momento transitório, em que a reestruturação posterior à crise ainda não havia se apresentado claramente, o que ocorre nos países de centro no final da década de 1970. Por exemplo: "Quando um Estado resiste, as multinacionais partem para outros lugares. Desta forma, se mundializa, no quadro do mercado mundial, a produção, a saber, a produção de mais-valor, sua realização e repartição. Portanto, se mundializa a luta de classes" (LEFEBVRE, 1976, p. 81-82. Grifo do original).
} 
metrópole, ao mesmo tempo deixando de reconhecê-las em seus direitos e sem permitir que criem suas próprias rotas de fuga emancipatórias.

Em $O$ Estado e a sociedade (LEFEBVRE et al, 2009), o problema fundamental para Lefebvre é a ideia de que todo programa político tem duas direções possíveis: ou ele propõe uma ação dentro de um certo enquadramento aceito, um enquadramento determinado pelo Estado, se encaixando no Estado existente; ou, alternativamente, ele propõe mudanças neste quadro estatal existente e até sua transformação completa. Ao buscar uma visão mais aprofundada da natureza do Estado, Lefebvre se posiciona a favor da segunda alternativa, da transformação do Estado, mirando o Estado capitalista e não o Estado no capitalismo como uma perspectiva teórica mais precisa. A partir desse pressuposto, Lefebvre se propõe a tarefa de compreender a gênese do Estado moderno e sua relação com o processo capitalista e, mais precisamente, com o crescimento econômico. Como já apontado acima, os séculos XVI e XVII constituem um ponto de inflexão muito significativo do início do conflito do capitalismo nascente com estruturas políticas herdadas do feudalismo e que vão ser decisivas em momentos posteriores.

Em $O$ Estado no mundo moderno (LEFEBVRE et al, 2009), Lefebvre aponta o alcance planetário do Estado hoje e a necessidade de se traçar essa história e de se compreender este processo de como essa invenção ocidental conquistou o mundo, sendo as relações entre o Estado moderno e o crescimento econômico um elemento central dessa história. Com o fortalecimento da indústria, há uma tendência inicial à autonomia do econômico, mas as diversas crises e estagnações trazem obstáculos e redefinem o papel do Estado, refortalecendo suas ligações (embrionárias, acrescentamos) com o processo capitalista ao longo da história. Deve-se acrescentar também que na maior parte dos países onde houve algum desenvolvimento capitalista mais substancial, observa-se um processo mais semelhante à trajetória dos países retardatários da Europa ocidental (Alemanha e Itália), nos quais o Estado tem um papel ainda mais central do que a simples garantia de mercados para a decolagem da revolução industrial na Inglaterra (e em certa medida nos EUA, onde também existe, como Lefebvre ressalta, uma autonomia relativa da esfera da produção em relação ao Estado, até que as grandes crises alterassem essa relação), sendo o caso brasileiro um exemplo proeminente na geografia histórica dos países semiperiféricos. "Do Estado que abre caminho para o crescimento ao Estado que administra o espaço do crescimento. Planejamento (da produção, do espaço) e semiplanejamento" (LEFEBVRE et al, 2009, p. 110)

E em $O$ espaço e o Estado (LEFEBVRE et al, 2009), o autor desenvolve uma trajetória histórica da relação entre o espaço e o Estado modernos, abordando como o Estado vai se tornando cada vez mais um grande agente por trás da produção do espaço, até chegar ao ápice de se tornar o agente principal, após maior aprofundamento da simbiose entre Estado e capital. Nessa perspectiva histórica, no início há um esforço grande de se garantir um domínio sobre o território, mantendo a autoridade do Estado-nação sobre a totalidade do mapa, criando instituições num 
nível hierárquico que culmina no poder central, através da polícia etc. (no Brasil um processo socioespacial repleto de conflitos e insurgências; sendo que a grande maioria dos Estados africanos ainda se encontra nesta fase, inseridos num ambiente global absolutamente distinto daquele que interagiu com a formação e o fortalecimento do aparato estatal de controle do território na maior parte do mundo). Posteriormente, há o início da produção de um espaço social que é eminentemente nacional, através de instituições diversas, desde as prefeituras até o próprio comércio na cidade, que cria uma ampla rede de agentes, todos de alguma forma interligados ao Estado. E, ao final, há uma preparação de terreno para o aprofundamento da acumulação capitalista, através da construção de estradas e do provimento das chamadas condições gerais de produção.

Não se trata, deste modo, de uma entidade abstrata engendrada pelos economistas, o crescimento, mas de um crescimento bem especificado, associando o crescimento do Estado ao crescimento da economia. Ele se interliga também à transformação do espaço que se reorganiza ao longo do século XIX nos grandes países industrializados, em torno dos caminhos de ferro, das estações, dos centros ferroviários. As cidades antigas entram na nova rede ou entram em declínio. Em seguida, as autoestradas e os aeroportos assumem o controle, se introduzem na rede e a remodelam. Um outro rearranjo, corolário do primeiro, resulta do fato de que a indústria dita pesada (que inclui a indústria química) pode se deslocar, se instalar longe das fontes de energia, sendo que esta faz surgir fluxos específicos. O que tende a uma reorganização do espaço, controlado pelo poder central (estatal). Deste modo se estabelece e se define a cada nova adição o espaço do Estado-nação. É neste espaço que se instala, numa notável sequência econômico-política com todas suas consequências, a indústria química, a indústria petroleira e petroquímica, depois a indústria nuclear e informática. $\mathrm{O}$ espaço dos Estados-nação tende a explodir; contudo, permanece a base sobre a qual se estabelecem os elementos do crescimento (LEFEBVRE, 1976, p. 55-56. Grifo do original).

A partir dessa leitura, torna-se possível antever como o Estado promove o crescimento econômico, se expande, concomitantemente, e altera sua relação com o espaço - aprofundando o controle sobre o território - nesta dinâmica. A preocupação de Lefebvre com o aspecto do crescimento e sua relação com o espaço também aparece em suas obras anteriores acerca da cidade e do urbano, sobretudo em relação ao desmantelamento da cidade por parte de um espaço industrializado e suas consequências políticas. No conjunto de trabalhos acerca do Estado, trata-se de uma perspectiva mais abrangente - abordando a relação Estado-espaço em geral, examinando também a reorganização escalar que começava a se esboçar naquele 
momento com a reconfiguração de um espaço mundial a partir do próprio Estadonação ${ }^{11}$. As formas que assumem esta relação Estado-espaço variam histórica e geograficamente, sendo que o fordismo/keynesianismo teve uma relação estreita com a experiência das Grandes Guerras nos países de centro, e a distribuição de benefícios e dos ganhos de produtividade bastante ligada a uma lógica de reconstrução do espaço interno da nação como forma ideologizada de garantir a coesão do suposto espaço de todos e ao mesmo tempo lidar com o trauma coletivo e o déficit (material e imaterial) pós-conflito. O fato do histórico do provimento de Habitação de Interesse Social por parte do Estado no âmbito do planejamento urbano ter suas raízes no atendimento à demanda por moradias por parte de veteranos da Primeira Grande Guerra na Inglaterra no Housing Act de 1919 (que levaria à construção de um milhão de moradias) é uma ilustração desta relação, que passaria a incorporar também reflexos da Guerra Fria no pós- $2^{a}$ Guerra, constituindo uma fonte de pressão por mecanismos distributivos na rivalidade externa e a ameaça à legitimidade do formato de hegemonia praticado internamente nos países de industrialização avançada naquele período.

A questão escalar também é central nas reflexões a respeito das alterações recentes na relação Estado-espaço, sendo que diversos autores no campo dos estudos urbanos se ocuparam desta análise relacionada à dinâmica do poder nas transformações das últimas décadas. Brenner (1998) propõe a noção de "arranjo escalar" partindo do "arranjo espacial" de Harvey (1982) como uma economia política das escalas espaciais, em que as características da esfera da acumulação e suas transformações engendram mudanças na dinâmica entre as escalas que se tornam mais ou menos proeminentes de acordo com as transformações econômicoespaciais. A globalização teria alterado profundamente esse arranjo, na direção de um protagonismo da escala local e urbana diretamente interligada ao nível global, que também se fortalece em detrimento do Estado-nação, que perde força neste período. Há também na literatura deste período do boom de estudos acerca da globalização uma preocupação com novos espaços estatais (BRENNER, 2004) e novas arquiteturas de poder em torno da escala transnacional, que se fortalecia, inclusive com argumentos de que se criava um domínio geográfico para além do Estado-nação, onde se intensificavam as trocas, as disputas e as relações e sobre o qual não existia uma estrutura de poder e governança correspondente. Centrar a abordagem da relação Estado-espaço na biopolítica como um aparato essencial do governo neoliberal (no comando e controle da população) envolve uma alteração no foco em relação a essa literatura. Reitera-se o papel do Estado-nação como um ente dotado de fortes capacidades e instituições, cujo impacto sobre o espaço e o território são muito significativos (através da macroeconomia, por exemplo), e

\footnotetext{
${ }^{11}$ Mais contemporaneamente, esta perspectiva, preocupada com o crescimento econômico e suas implicações espaciais, ganha uma ligação com a proeminência da questão ambiental, que fundamentalmente envolve uma série de implicações da expansão capitalista no espaço, sua intensificação, e suas relações com a esfera estatal que continua a prover as bases para esta dinâmica.
} 
aborda-se a globalização como resultado da interação entre Estados-nação, como fica claro neste início de século a partir do protagonismo chinês na reprodução capitalista em larga escala e seu impacto geoeconômico a partir da criação de fortes entrelaçamentos em cadeias globalmente organizadas, mas altamente influenciadas por um núcleo de comando constituído no Estado-nação chinês. Não se trata de um simples retorno ao nacionalismo metodológico característico de abordagens preocupadas com escalas mais amplas, como é o caso de grande parte da literatura acerca da dinâmica centro-periferia ou da teorização de Wallerstein (1974) sobre o sistema-mundo, mas de reconhecer que o plano global se torna concreto e ganha proeminência através da força da ação efetiva das instituições nacionais e a subsunção da atuação destas aos imperativos daquele. A ligação direta da cidade e da região com o plano global ${ }^{12}$ passa necessariamente por instituições, leis e políticas comandadas pelo Estado-nação, sendo que as dinâmicas que partem destas instituições nacionais alteram profundamente este trânsito entre cidade/região e a escala global ${ }^{13}$.

Além desta perspectiva escalar, trazer a perspectiva mais recente da biopolítica a partir de Foucault (2008) e de suas leituras em Dardot e Laval (2014), bem como nos trabalhos de Hardt e Negri (2001; 2005; 2009), envolve também complementar o enfoque sobre o território com a dimensão do controle da população por parte do Estado. Num primeiro momento, isso se dá através de mecanismos disciplinares/disciplinadores e coercitivos (FOUCAULT, 1987), em seguida, sofistica-se para formas de internalização individual do próprio policiamento e, sobretudo, de formas de ação cotidianas moldadas pelo cálculo econômico. Passa-se de uma relação dominada pelo encontro entre a autoridade e o controle do território com a estruturação do policiamento no controle disciplinar da população, para a adição dos dispositivos de moldagem de formas de comportamento a partir de sinalizações do Estado em estruturas de incentivos e desincentivos que os indivíduos precisam incorporar na sua conduta - o que se torna uma relação entre Estado e espaço socialmente produzido, para além do território. O primeiro nível deste percurso - o aparato da força policial - permanece em voga como uma ameaça constante para aqueles que não se encaixem e venham a desrespeitar o esquema de regras colocado no último ${ }^{14}$.

\footnotetext{
${ }^{12}$ Esta tese se propagou amplamente no debate acerca do impacto da globalização nas cidades, frequentemente com o argumento (correto, embora incompleto) de que a metrópole constituía um portal de ligação e acesso direto ao espaço da globalização.

${ }_{13}$ Pouco adianta uma estratégia local/regional de desenvolvimento regional a partir da atração de investimentos externos buscando inserir a economia de determinada região em cadeias produtivas globalmente organizadas, se a legislação trabalhista ou ambiental, por exemplo, determinada em escala nacional, não for atrativa o suficiente para os capitais em busca de melhores oportunidades de inversão visando sua reprodução em padrões mais elevados.

${ }^{14}$ Sobre a relação direta entre neoliberalismo, violência policial e encarceramento da população pobre no contexto norte-americano, ver Wacquant $(2001 ; 2009)$.
} 
Sob o neoliberalismo, em função da restrição das possibilidades de inserção às vias que o mercado oferece (e da precarização e instabilidade inerentes a elas), bem como do enfraquecimento dos mecanismos de proteção social, este policiamento passa pela necessidade de tratar com a violência das políticas de tolerância zero a parcela da população que tende a escorregar nessa direção, inúmeras vezes em função da própria precariedade das possibilidades de inserção através das regras impostas. Há, assim, um aumento do encarceramento concomitante ao fortalecimento deste controle biopolítico através da construção de subjetividades, fortalecendo também o aparato disciplinador sobre o qual ele acrescenta uma nova camada. Na metrópole brasileira, este biopoder envolve a necessidade de controle de uma parcela da população historicamente excluída que também atua por meio da mesma estrutura de incentivos e desincentivos formadora de indivíduos que age de acordo com cálculos de escolha racional utilitarista, mas com um elemento disciplinar e corporal mais forte, muitas vezes fora das próprias regras que o Estado de direito impõe nesta atuação, e com um elemento racista bastante marcante. Esta necessidade de controle dessa parcela da população ganha evidência no contexto das manifestações pós-junho de 2013 e, mais amplamente, na conjuntura urbana atual de aceleradas transformações decorrentes da valorização imobiliária, que aumenta a pressão por projetos reestruturadores definidos em função de interesses dos setores que se beneficiam da renda da terra aumentada e mobilizada pelo setor financeiro.

A insuficiência da ação na direção de correções e reparações de percursos históricos que engendram resultados presentes demarca o neoliberalismo em sua experiência na América Latina, por interagir com um quadro histórico cujos frutos são ignorados, lançando para o jogo do mercado a criação de saídas e soluções. Se as falhas de mercado prevalecem, como ocorre no caso da habitação, a reação do Estado já numa fase mais avançada da experiência de governança neoliberal com um nexo inclusivo via mercado é o desenho de planos que visam corrigir tais falhas, mantendo o mercado nas canalizações de soluções, seja no formato das parcerias público-privadas, ou no provimento direto por parte do Estado de condições que permitam que demanda encontre oferta dentro do próprio mercado - sendo o Programa Minha Casa Minha Vida uma boa ilustração dessa lógica, com consequências significativas para a produção do espaço na metrópole.

É sobre uma redefinição na relação entre Estado e espaço que o neoliberalismo urbano se assenta enquanto projeto transformador da metrópole, o que traz a necessidade de uma reinserção da dimensão territorial e da geografia do poder nesse debate. Os processos políticos recentes que emanam da metrópole brasileira apontam para um terreno fértil às pesquisas empíricas com foco no dinamismo e no vigor democrático que se constrói por fora do Estado em ressonância com posturas de defesa do aprofundamento e da radicalização da democracia, cujos núcleos dinâmicos se situam justamente nestes domínios autônomos (ABENSOUR, 1998). 


\section{Considerações Finais}

Propusemos neste artigo uma leitura das funções governamentais do processo neoliberal, que se acopla a uma retórica contraditória de minimização do Estado enquanto fortalece partes selecionadas de sua ação, que geram consequências importantes para as relações Estado-espaço-sociedade. Buscamos também fazer um breve apanhado do histórico teórico-discursivo do pensamento econômico-social que dá sustentação a este projeto de governo e de sociedade, evocando a discussão lefebvriana acerca do Estado, além da abordagem antropológica mais recente de David Graeber. Este panorama convoca um aprofundamento posterior em agendas de pesquisa acerca das associações, efetuadas em planos diversos, entre poder, Estado, capital e produção do espaço. Tal abordagem pode, através de um reconhecimento da natureza múltipla e das formas distintas e entrelaçadas de exercício do poder, propor cartografias sociais e mapeamentos de associações entre estas modalidades interdependentes e sua agência em processos socioespaciais contemporâneos, inclusive a partir da ação concreta de movimentos sociais e outros agentes transformadores em potencial, também diversos.

$\mathrm{O}$ ato de governar, mas também de manipular, controlar, dominar outros indivíduos ou grupos com o intuito de atingir objetivos próprios, inclusive a capacidade de extrair valor do trabalho alheio, de fazer com que os outros trabalhem para si, para sua acumulação (de riquezas, de mais poder), ocorre de forma múltipla em agenciamentos diversos e em situações e espaços sociais variados. O poder tem um atributo cumulativo fundamental, é ferramenta primordial para seu próprio acúmulo, mas não é autorreprodutor. Sua reprodução envolve necessariamente a mobilização de mecanismos que instrumentalizam elementos exógenos subsumidos e dominados, e é interdependente em suas diversas formas de exercício. Não se reduz à autoridade do Estado, mas tem nesta um agenciador de forças fundamental na definição da trama mais ampliada, e envolve uma dinâmica de reprodução social criadora de divisões, hierarquias, desigualdades, segregações, isolamentos e outras formas negativas de diferença social que são efeito destas relações de poder entre grupos e indivíduos. Entre estes agenciamentos entrelaçados, podemos propor uma tipologia preliminar, na qual se inseririam: aqueles que detêm grandes patrimônios e riquezas, sejam líquidos ou não; que controlam meios de produção e a capacidade de agenciar formas diversas de se reproduzir capitais; que se encontram em posições de controle de instituições financeiras; que detêm a capacidade de controlar e influenciar o Estado; que são grandes proprietários de terras e ativos imobiliários; possuidores de armamentos (inclusive no domínio que, supostamente, escapa ao controle do Estado); que são grandes credores do Estado; e que mobilizam formas de produzir valores, ideologia e produção simbólica. É nessas tramas que se localizam as ações encadeadas que dão conteúdo prático e cotidiano a agenciamentos hegemônicos mais amplos tal qual o neoliberalismo em suas 
variações geográficas diversas, sendo seu (re)conhecimento passo imprescindível para projetos visando transformações democráticas de tais ordens.

\section{Bibliografia}

ABENSOUR, Miguel. (1998) A democracia contra o Estado: Marx e o momento maquiaveliano. Belo Horizonte: Editora UFMG.

BARNES, Trevor; SHEPPARD, Eric. (2010)'Nothing includes everything': towards engaged pluralism in Anglophone economic geography. Progress in Human

Geography, $34 \quad$ (2). Disponível em: http://blogs.ubc.ca/trevorbarnes/files/2015/11/published-version.pdf >. Acessado em: nov. 2015.

BRENNER, Neil. (1998) Between fixity and motion: accumulation, territorial organization and the historical geography of spatial scales. In: Environment and Planning D: Society and Space, 16, 5, 1998. Disponível em: http://sociology.as.nyu.edu/docs/IO/222/Brenner.EPd.1998.pdf (consultaemagosto/2014).

(2004) New state spaces: urban governance and the rescaling of statehood. Oxford University Press.

DARDOT, Pierre; LAVAL, Christian. (2014)The new way of the world: on neoliberal society. Nova York: Verso.

DELEUZE, Gilles; GUATTARI, Felix. (1995) Mil platôs: capitalismo e esquizofrenia. Vol. 1. Rio de Janeiro: Ed. 34.

FRIEDMAN, Milton. (1962) Capitalism and freedom. University of Chicago Press. FOUCAULT, Michel. (2008) O nascimento da biopolítica. São Paulo: Martins Fontes.

GRAEBER, David. (2011) Debt: the first 5000 years. Nova York: Melville House. HARDT, Michael; NEGRI, Antonio. (2001) Império. Rio de Janeiro: Record. . (2005) Multidão: guerra e democracia na era do Império. Rio de Janeiro:

Record.

. (2009) Commonwealth. Harvard University Press.

HARVEY, David. (1982) Limits to capital. Londres: Basil Blackwell.

Boitempo.

(2011) O enigma do capital: e as crises do capitalismo. São Paulo:

HAYEK, Friedrich. (2010) O caminho da servidão. São Paulo: Instituto Ludwig von Mises Brasil.

HOBSBAWM, Eric. (1968) Industry and empire: from1750 to the present day. Londres: Penguin.

HOLSTON, James. (2013) Cidadania insurgente: disjunções da democracia e da modernidade no Brasil. São Paulo: Cia. das Letras.

LEFEBVRE, Henri. (1974) La production de l'espace. Paris: Anthropos. 
(1976) De l'État. Paris: Union generale.

(1976b) De l'État, vol 2: De Hegel à Mao par Staline. Paris: Union

Génerale.

. (1977) De l'État, vol 3: Le mode de productionétatique. Paris: Union Génerale.

- (1978) De l'État, vol 4: Lescontradictions de l'Étatmoderne, La dialectique de l'état. Paris: Union Génerale.

LEFEBVRE, Henri; BRENNER, Neil; ELDEN, Stuart (Org.). (2009) State space world: selected essays. University of Minnesota Press.

PECK, Jamie. (2010) Constructions of neoliberal reason. Oxford University Press.

WACQUANT, Loïc. (2001) The penalisation of poverty and the rise of neoliberalism. European Journal on Criminal Policy and Research 9. pp. 401-412. . (2009) Punishing the poor: the neoliberal government of social insecurity. Durham: Duke University Press.

WALLERSTEIN, Immanuel. (1974) The modern world-system. San Diego: Academic.

WARREN, Bill. (1980) Imperialism: Pioneer of capitalism. Londres: Verso. 